\title{
Educational Needs for Clinical Dental Hygienists' Dental Hygiene Core Competencies
}

\author{
Moon Sil Choi \\ Department of Dental Hygiene, Songwon University, Gwangju, Korea
}

Objective: The purpose of this study is to investigate the clinical skill proficiency in the core dental hygiene competency of dental hygienists.

Methods: One hundred dental hygienists living in Gwangju and Jeollanam-do participated in the study. Data were analyzed with IBM SPSS Statistics for ver. 20.0 (IBM Co., Armonk, NY, USA) for general characteristics, execution of core dental hygiene competency, frequency analysis of the questionnaire, and correlations of one-way ANOVA and Pearson were analyzed.

Results: The ranking of the core dental hygiene competency skill requirement was temporary filling and removal (3.43 \pm 1.40$)$, toothbrushing education $(3.38 \pm 1.36)$, and dental radiography $(3.36 \pm 1.37)$. In relation to core competencies for dental hygiene by experience, temporary crown making, temporary filling and removal, removal and installation of temporary attachments, and infection control in 5 years or more were found to exist $(p<0.05)$. In the correlation between dental hygiene core competency skill requirement, age and radiography showed a significant positive correlation, and experience and temporary filling and removal showed a significant negative correlation $(p<0.05)$.

Conclusion: There were significant differences in the general characteristics of dental hygienists and educational requirements by age and experience. It is necessary to improve various educational programs and evaluation methods to achieve students' clinical competency in schools.

Keywords: dental hygienists, evaluation, competence

\section{Introduction}

One of the things that are being emphasized as the direction and task of human resource development policies in countries around the world is the cultivation of core competencies through

\section{Corresponding author Moon Sil Choi}

E-mail: ms9106@hanmail.net

(iD) https://orcid.org/0000-0003-3256-2481

Received December 3, 2021, Revised December 23, 2021 , Accepted December 24, 2021 the school curriculum. In recent years, various efforts are being made to develop core competencies in order to nurture job-related talents according to social demands [1].

The present core competency can be defined as an essential requirement for living in the future beyond the competency for successful job performance [2].

Under this environment, health and medical departments manage the quality of education through the 'Korea Dental Education Evaluation Institute', 'Korea Nursing Education Evaluation Institute', and 'Korea Medical Education Evaluation Institute' to manage the quality of education and dental hygiene education. It is also affected [3].

Copyright (C) 2021. Korean Academy of Preventive Dentistry.

This is an Open Access article distributed under the terms of the Creative Commons Attribution Non-Commercial License (http://creativecommons.org/licenses/ by-nc/4.0) which permits unrestricted non-commercial use, distribution, and reproduction in any medium, provided the original work is properly cited. 
The Korean Dental Hygienists Association also formed the Preparatory Committee of the Korea Dental Hygiene Education Evaluation Institute and has been making continuous efforts to develop an evaluation system related to dental hygiene education. Dental hygiene (academic) is a discipline that aims for an integrated education of theory and practice, and once a license is obtained after graduation, treatment and various tasks are performed at dental hospitals and clinics, local communities, and specialized institutions. For this, practical education in a clinical environment is essential, and it is necessary to improve the quality of dental services by developing and educating them. In this context, at the 2014 Korean Dental Hygiene (Department) Faculty Council, the core competencies of dental hygiene students were divided into 4 areas: professionalism, communication, clinical practice, and community and health promotion. Sub-detailed competencies were also presented in the clinical dentistry area [4], and then, at a public hearing, 'core dental hygiene competency techniques' were presented to evaluate clinical work performance, which is one area of dental hygiene evaluation [5].

In fact, most new dental hygienists who start working at medical institutions after graduation receive education through curriculum classes or clinical practice at school. In practice, dental hygiene and dental hygiene, which must be performed in the clinical field after graduation, do not show well, so dental hospitals and clinics invest time in re-education for a certain period to adapt and apply the internship system.

If they do not have the appropriate level of work performance, the damage caused by this will act as a burden on medical institutions, patients, and dental hygienists. Efforts to cope with the situation and changes in the clinical field and to develop competencies that can be applied immediately after graduating from school are essential. To this end, it is necessary to analyze whether clinical dental hygienists are well equipped with a certain level of core competencies for dental hygienists and to understand their educational needs. Because the degree of the core competency of clinical dental hygienists is not only an indicator that can confirm the performance of dental hygiene education, but it can also be used as confirmation data on whether or not their role in clinical practice is being performed well after graduation, and ultimately, dental medical service. This is because it has a direct impact on quality management.

Looking at previous studies, the satisfaction and stress related to the clinical practice of dental hygiene (department) students, factors affecting self-evaluation of core competencies of preliminary graduates, educational requirements for clinical practice, the usefulness of student practice, and perceptions of practice tasks. Although there are studies [6-8] that analyzed such factors, there are few studies that analyzed the retention of dental hygiene core competency and education requirements.

This study was conducted to provide basic data to secure education and programs that need further development in school education by making a subjective evaluation of core dental hygiene competency in clinical settings.

\section{Materials and Methods}

\section{Research object}

In this study, from December 7 to December 30, 2019, a random sample of dental hospitals and clinics where graduates of our school in Gwangju and Jeollanam-do worked were sampled and phone calls were made with a head-level dental hygienist. The purpose of the study was explained and a questionnaire was asked for each number of people working.

The questionnaire was conducted without going through a separate review by the Research Ethics Deliberation Committee because a self-filling questionnaire was conducted after obtaining consent signatures from the research subjects. There were 130 subjects who responded to the questionnaire. 111 subjects were calculated using the $G^{*}$ power 3.1 program (medium effect size 0.3 , significance level 0.05 , power $95.0 \%$ ). In consideration of the dropout rate, 120 copies (93\%) were collected, and 100 copies were analyzed excluding the questionnaires that were answered insincerely or by non-dental hygienists.

\section{Research tools}

Although the legal duties of dental hygienists are set as the basis, they are actually performing delegated duties related to medical assistance, so the questionnaire questions were modified and used focusing on the 'core dental hygiene competency skills' presented by the Korea Dental Hygiene Evaluation Institute. Preparation of necessary medical records in the clinical field, vital signs, dental $\mathrm{x}$-ray, alginate impression taking, study model, instrument sharpening, scaling, polishing (rubber cup), toothbrushing education, fluoride therapy, sealant, rubber dam, gingival code insertion and removal, matrix band \& retainer, temporary teeth production, a temporary filling, temporary attachment, patient counseling, wire installation, sterilization infection control, and general characteristics were composed. It consists of charging, temporary attachment, patient consultation, wire installation, infection control problems, and general characteristics. It consists of 4 general characteristics and 20 medical related items. The proficiency was indicated on a Likert 5-point scale as a treatment task performed a lot in actual clinical practice. 'Strongly not' 1 point, 'disagree' 2 points, 'normal' 3 points, 'yes' 4 points, and 'very much' 5 points. 


\section{Data analysis}

The collected data is based on IBM SPSS Statistics for ver. 20.0 (IBM Co., Armonk, NY, USA) was used for statistical analysis. The self-assessed proficiency reliability of the dental hygienist's core competency was Cronbach's Alpha $(\alpha=0.938)$. For general characteristics, frequency analysis was performed, and a one-way ANOVA test was performed for differences between general characteristics and core competencies. Pearson's correlation was performed on the correlation between general characteristics and the core competencies performed.

\section{Results}

\section{General characteristics of study subjects}

The general characteristics of the study subjects are shown in Table 1. A total of 100 subjects were studied, and most of them were women $(92.0 \%)$. Most of them were 26-30 years old (30.0\%), 20-25 years old (26.0\%), 31-35 years old (20.0\%), followed by $36-40$ years old (12.0\%) and 41 years old or older $(12.0 \%)$. As for the final educational background, $57.0 \%$ had a three-year degree, followed by a four-year degree with $43.0 \%$.

\section{Ranking of core dental hygiene competency}

The ranking of dental hygiene core competencies is shown in Table 2. Temporary filling and removal among the core competencies for dental hygiene were temporary filling and removal (3.43 \pm 1.40$)$, brushing education (3.38 \pm 1.36$)$, dental radiography (3.36 \pm 1.37$)$, installation and removal of temporary attachments $(3.28 \pm 1.43)$, infection control $(3.24 \pm 1.37)$, temporary tooth preparation $(3.23 \pm 1.41)$, and tartar removal $(3.23 \pm 1.39)$ were in order. It was confirmed that the rubber

Table 1. General characteristics $(\mathrm{N}=100)$

\begin{tabular}{llr}
\hline Characteristic & \multicolumn{1}{c}{ Division } & $\mathrm{N}(\%)$ \\
\hline Sex & Male & $8(8.0)$ \\
& Female & $92(92.0)$ \\
Age & $20-25$ & $26(26.0)$ \\
& $26-30$ & $30(30.0)$ \\
& $31-35$ & $20(20.0)$ \\
& $36-40$ & $12(12.0)$ \\
Career $(y r)$ & $\geq 41$ & $12(12.0)$ \\
& $1-3$ & $22(22.0)$ \\
& $4-6$ & $31(31.0)$ \\
& $7-9$ & $17(17.0)$ \\
& $10-12$ & $12(12.0)$ \\
& $\geq 13$ & $18(18.0)$ \\
Education & College $(3 \mathrm{yr})$ & $57(57.0)$ \\
& Bachelor $(4 \mathrm{yr})$ & $43(43.0)$
\end{tabular}

dam installation $(3.03 \pm 1.42)$ required the lowest skill level.

\section{Dental hygiene core competency skill requirements according to experience and age}

The core competencies according to experience and age are shown in Table 3. There were significant differences in dental radiography, diagnostic model making, toothbrushing education, rubber dam installation, temporary tooth production, temporary filling and removal, temporary attachment and removal, and infection control in career history $(\mathrm{p}<0.05)$. In the age group, there were significant differences in manual tool polishing, calculus removal, fluoride application, sealant, and diaphragm method $(\mathrm{p}<0.05)$. For those with $10-12$ years of experience $(3.66 \pm 1.07)$, the skill requirements for dental radiography, diagnostic modeling, calculus removal, toothbrushing education, and rubber dam installation were high $(p<0.05)$. In terms of age, the skill requirements for manual tool polishing, tartar removal, fluoride application, and sealant were high among the 36-40 age group.

\section{Correlation between general characteristics and core competencies of dental hygiene}

The correlation between the major variables is shown in Table 4. Age and radiography showed a significant positive cor-

Table 2. Ranking of core dental hygiene competency $(N=100)$

\begin{tabular}{|c|c|c|}
\hline Division & $M \pm S D$ & Ranking \\
\hline Temporary filling and removal & $3.43 \pm 1.40$ & 1 \\
\hline Toothbrushing education & $3.38 \pm 1.36$ & 2 \\
\hline Dental x-ray taking & $3.36 \pm 1.37$ & 3 \\
\hline $\begin{array}{l}\text { Temporary attachment application and } \\
\text { removal }\end{array}$ & $3.28 \pm 1.43$ & 4 \\
\hline Sterilization and infection control & $3.24 \pm 1.37$ & 5 \\
\hline Making temporary crown & $3.23 \pm 1.41$ & 6 \\
\hline Scaling & $3.23 \pm 1.39$ & 7 \\
\hline $\begin{array}{l}\text { Orthodontic wire application and } \\
\text { removal }\end{array}$ & $3.16 \pm 1.39$ & 8 \\
\hline Gingival code insertion and removal & $3.16 \pm 1.36$ & 9 \\
\hline Polishing (rubber cup) & $3.15 \pm 1.42$ & 10 \\
\hline Study model making & $3.15 \pm 1.40$ & 11 \\
\hline Alginating impression taking & $3.14 \pm 1.40$ & 12 \\
\hline Vital sign & $3.13 \pm 1.39$ & 13 \\
\hline Fluoride therapy & $3.12 \pm 1.38$ & 14 \\
\hline Instrument sharpening & $3.10 \pm 1.38$ & 15 \\
\hline Patient counseling/education & $3.09 \pm 1.40$ & 16 \\
\hline History taking & $3.09 \pm 1.36$ & 17 \\
\hline Sealant & $3.06 \pm 1.39$ & 18 \\
\hline Matrix band and retainer & $3.05 \pm 1.38$ & 19 \\
\hline Rubber dam isolation & $3.03 \pm 1.42$ & 20 \\
\hline
\end{tabular}

$\mathrm{M} \pm \mathrm{SD}:$ mean \pm standard 


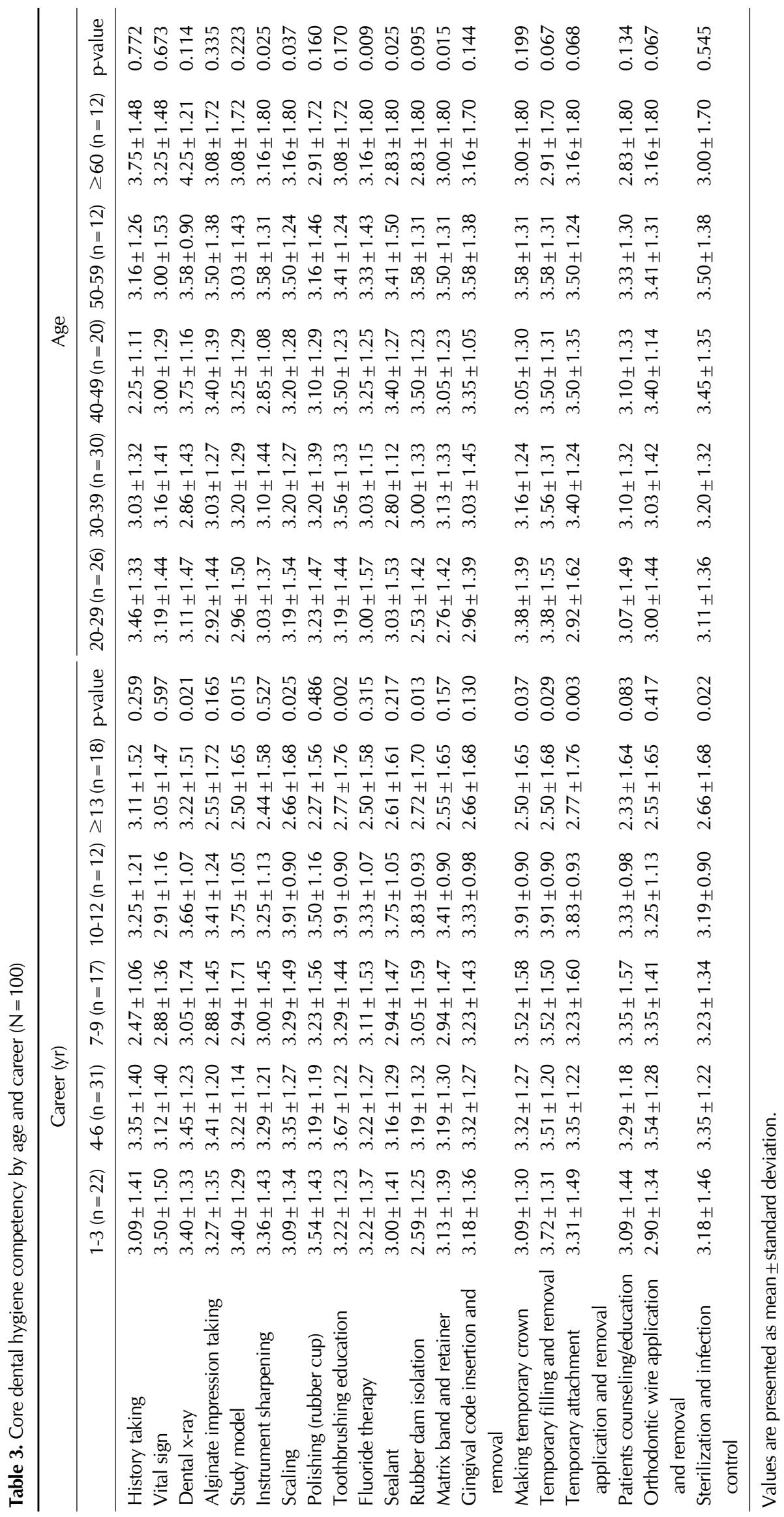


Table 4. Correlations among core dental hygiene competency $(\mathrm{N}=100)$

\begin{tabular}{|c|c|c|c|c|c|c|c|c|c|c|}
\hline Variable & Age & Career & Education & $\begin{array}{c}\text { X-ray } \\
\text { taking }\end{array}$ & Scaling & $\begin{array}{l}\text { Toothbrushi } \\
\text { ng education }\end{array}$ & $\begin{array}{c}\text { Temporary } \\
\text { filling and } \\
\text { removal }\end{array}$ & $\begin{array}{l}\text { Sterilization } \\
\text { and infection } \\
\text { control }\end{array}$ & $\begin{array}{l}\text { Making } \\
\text { temporary } \\
\text { crown }\end{array}$ & $\begin{array}{l}\text { Temporary } \\
\text { attachment } \\
\text { application } \\
\text { and removal }\end{array}$ \\
\hline Age & 1 & & & & & & & & & \\
\hline Careerr & 0.172 & 1 & & & & & & & & \\
\hline Education & 0.120 & 0.023 & 1 & & & & & & & \\
\hline X-ray taking & $0.287 * *$ & -0.033 & 0.008 & 1 & & & & & & \\
\hline Scaling & 0.025 & -0.051 & -0.188 & $0.231^{*}$ & 1 & & & & & \\
\hline Toothbrushing education & -0.014 & -0.093 & 0.069 & $0.216^{*}$ & $0.685^{* *}$ & 1 & & & & \\
\hline $\begin{array}{l}\text { Temporary filling and } \\
\text { removal }\end{array}$ & -0.067 & $-0.222 *$ & 0.022 & $0.223^{*}$ & $0.648 * *$ & $0.714^{* *}$ & 1 & & & \\
\hline $\begin{array}{l}\text { Sterilization and } \\
\text { infection control }\end{array}$ & 0.028 & -0.070 & 0.010 & $0.220^{*}$ & $0.592 * *$ & $0.748 * *$ & $0.740 * *$ & 1 & & \\
\hline Making temporary crown & -0.040 & -0.075 & 0.002 & 0.196 & $0.692 * *$ & $0.670 * *$ & $0.689^{* *}$ & $0.739 * *$ & 1 & \\
\hline $\begin{array}{l}\text { Temporary attachment } \\
\text { application and removal }\end{array}$ & 0.079 & -0.077 & -0.057 & $0.271^{* *}$ & $0.716^{* *}$ & $0.747^{* *}$ & $0.622^{* *}$ & $0.588^{* *}$ & $0.545^{* *}$ & 1 \\
\hline
\end{tabular}

relation coefficient $(\mathrm{r}=0.287, \mathrm{p}<0.01)$. Career and temporary replenishment and elimination showed a significant negative correlation $(\mathrm{r}=-222, \mathrm{p}<0.05)$.

\section{Discussion}

This study investigated the educational requirements for dental hygiene core competencies that students must have before graduation in order to strengthen their competency [9]. Temporary filling and removal $(3.43 \pm 1.40)$, toothbrushing education $(3.38 \pm 1.36)$, and dental radiography $(3.36 \pm 1.37)$ responded in order of proficiency. In the study of Chae et al. [10], the response that the skill requirement for toothbrushing education for each subject was the second most important among the core basic competencies supports the results of this study. It is worth paying attention to the results of the responses that ultrasound scaling, brushing education, and guidance on the following treatment should be skilled. This is supported by the study results according to each subject's brushing, brushing method, and bristles [11-13].

I think that additional and more diverse research is needed, considering that the main task of dental hygienists is preventive dentistry, which requires a lot of weight and more skill.

The requirement for proficiency in dental radiography was also high. It is an essential process for diagnosing diseases after oral examination [11], but high proficiency is required. It is considered that they responded that education was necessary for terms of use with the introduction of radiographic imaging equipment. As a result of examining the average difference between career and dental hygiene core competency, dental radiography
(3.66 \pm 1.07$)$, diagnostic model production $(3.75 \pm 1.05)$, calculus removal (3.91 \pm 0.90$)$, toothbrushing education (3.91 \pm 0.90$)$, rubber dam installation $(3.83 \pm 0.013)$, temporary tooth production (3.91 \pm 0.90$)$, temporary filling and removal (3.91 \pm 0.90$)$, temporary attachment and removal $(3.83 \pm 0.93)$, and infection control (3.19 \pm 0.90$)$ must be performed by a person with $10-12$ years of experience. It was actively performed and it was statistically significant $(\mathrm{p}<0.05)$ as it required proficiency. As a result of examining by age, manual tool polishing $(3.58 \pm 1.31)$, tartar removal (3.50), fluoride application (3.33 \pm 1.43$)$, sealant (3.41 \pm 1.50$)$, and bulkhead method $(3.50 \pm 1.31)$ showed a higher skill requirement in the late 30 s age group, which was statistically significant. It can be seen that the working behavior of dental hygienists is that as their age and experience increase, they do more tasks that can be done alone rather than as simple assistants.

In a study by Lee et al. [14] and others, it was found that oral health education and dental preventive treatment were performed the most in dental hospitals and clinics as the age increased. The results of the report that the dental care cooperation work is performed lower as the age increases are supported by the report. In the correlation between general characteristics and core competencies of dental hygiene, the correlation between major variables shows a significant positive correlation coefficient with age and radiography $(\mathrm{r}=0.287, \mathrm{p}<0.01)$.

It can be interpreted that the higher the importance of the task, the higher the need for education and training. Career and temporary replenishment and removal showed a significant negative correlation $(\mathrm{r}=-0.222, \mathrm{p}<0.05)$.

Taken together, these results suggest that strengthening the competency of dental hygienists is an important factor for ach- 
ieving job performance and is intended to provide high-quality medical services to patients.

In other academic fields in the health and medical field, evaluation institutes are being operated to manage the quality of education in order to strengthen competency. Therefore, dental hygiene educational institutions and research institutes should actively improve various educational programs and evaluation methods [15] using cutting-edge educational media to acquire practical and professional skills for strengthening dental hygiene competency.

Therefore, it is necessary to provide sufficient education on core competencies with high importance and frequency of work so that they can quickly adapt to work. In addition, it is necessary to update the educational contents according to the speed of change in the field of practice and to minimize the gap between theory and practice.

The limitation of this study is that it was conducted for some regional dental hygienists, so there is a limit to generalization. Moreover, it is a time when it is necessary to agree on core competencies in legal and delegated tasks.

It is significant in that the subjective skill requirements of clinical dental hygienists were identified and evaluated as a representative item of dental hygiene core competency.

\section{Conclusion}

This study tried to find out the educational requirements for dental hygiene core competency most demanded by clinical dental hygienists by modifying the questionnaire on 'core dental hygiene competency' presented by the Korea Dental Hygiene Evaluation Institute.

Data collected from December 7 to December 30, 2019 from 100 dental hygienists randomly selected from Gwangju and Jeollanam-do were analyzed in IBM SPSS Statistics for ver. 20.0 (IBM Co.), the following results were obtained.

1. Core dental hygiene competency education requirement ranking is temporary filling and removal $(3.43 \pm 1.40)$, toothbrushing education (3.38 \pm 1.36 ), dental radiography (3.36 \pm 1.37$)$, temporary attachment removal and installation (3.28 \pm 1.43$)$, infection control $(3.24 \pm 1.37)$ appeared in the order.

2 . In relation to dental hygiene core competency by career, there was a statistically significant difference in the temporary crown making, temporary filling and removal, temporary attachment removal and installation, and infection control in 5 years or more $(\mathrm{p}<0.05)$.

3. In relation to the core competencies of dental hygiene by age, there was a statistically significant difference in the partition wall method, manual polishing, tartar removal, fluoride application, and sealant $(\mathrm{p}<0.05)$.
4. In the correlation between dental hygiene core competency skill requirement, age and radiograph showed a significant positive correlation, and experience and temporary filling and removal showed a significant negative correlation $(\mathrm{p}<0.05)$.

There were significant differences in the general characteristics of dental hygienists and educational requirements by age and experience. It is necessary to improve various educational programs and evaluation methods to achieve students' clinical competency in schools.

\section{Acknowledgements}

This study was supported by research fund from Songwon University 2020 [A2020-51].

\section{Conflict of Interest}

No potential conflict of interest relevant to this article was reported.

\section{ORCID}

Moon Sil Choi, https://orcid.org/0000-0003-3256-2481

\section{References}

1. Kim SY, Kim BK, Chae MJ. Analysis of education needs on nursing core competencies of nursing college students using ImportancePerformance Analysis: a case of college A. J Vocat Educ Res 2019; 38:115-35.

2. Park SJ, Song YS. A study on development of a core competencies tool of university students according to specialized university. J Vocat Educ Train 2016;19:79-107.

3. Bae SM, Shin SJ, Jang JH, Chung WG, Mun SJ. Implementation of assessment in a competency-based dental hygiene science education. Iksan: Korean Association of Dental Hygiene Professors; 2014.

4. Mun SJ, Noh HJ, Bae SS, Kim SK, Jeong JH. Development of clinical dental competencies in dental hygienists. J Korean Soc Dent Hyg 2018;18:281-93.

5. Lee MS, Yeom DY, Shin KR; Korean Dental Hygienists Association. Public hearing for Korean dental hygiene education accreditation system. Seoul: The National Assembly of The Republic of Korea; 2014:1-65.

6. Heo NS, Lee YH. Study about the relation between clinical practice stress, satisfaction and self-concept of dental hygiene department students. J Korean Soc Dent Hyg 2018;18:399-410.

7. Bae SM, Shin SJ, Shin BM, Choi YK, Son JH. Factors affecting the level of self-core competencies of dental hygiene students. J Korea Contents Assoc 2019;19:402-11.

8. Kim HM, Jeong MA. A concept mapping study on factors inducing dental hygiene student's activeness during clinical practice. 
J Korea Contents Assoc 2020;20:359-66.

9. Park JH, Lee YH. Influence of dental hygienists' core competencies on job performance. J Dent Hyg Sci 2017;17:142-9.

10. Chae SH, Noh HJ, Jeong GW, Kim HN, Maeng HM, Cho YS, et al. Research on dental hygienists' clinical skill proficiency in core dental hygiene competency. J Korean Soc Dent Hyg 2016;16: 651-60.

11. Kang YJ. Importance of job tasks, job training requirement and work satisfaction felt by dental hygienists. J Korean Acad Dent Hyg Educ 2005;5:1-13.

12. Shin SC, Chang YS, Kim JS, Lee KH. A study on the effect of sonic vibration toothbrush that has omnidirectional bristles on chil- dren's oral hygiene. Int J Clin Prev Dent 2019;15:33-7.

13. Na HJ. Changes in patient hygiene performance index after brushing 3 electric tooth brushes. Int J Clin Prev Dent 2019;15:68-71.

14. Lee HJ, Kim SJ, Kim YS, Jeon JG, Chang KW. Published erratum: relationship between job competency, core self-evaluation, and job performance in dental hygienists. J Korean Acad Oral Health 2013;37:257.

15. Choi YK, Lim KO, Han YK, Bae SM, Shin BM, Ahn SY, et al. Study on clinical dental hygiene in Korea based on analysis of clinical dental hygiene curriculum of fones school in the United States. J Dent Hyg Sci 2017;17:123-33. 